\title{
Medical students interact with multicultural patients to learn cultural diversity
}

\author{
HyeRin Roh $^{1,2}$ and Lauren Nirta ${ }^{1}$
}

\author{
${ }^{1}$ Department of Medical Education and ${ }^{2}$ The Institute for Medical Humanities, Inje University College of Medicine, \\ Busan, Korea
}

Purpose: The aim was to present our experiences implementing a cultural diversity (CD) education program.

Methods: The authors held a 4-hour CD class for third-year medical students. The aim of the class was to facilitate students to realize and reflect on the importance of $C D$ on healthcare delivery in Korea. The class was comprised of an orientation about $C D$ in Korea, physicians and multicultural guests sharing their experiences with students, small group discussion, and O\&A panel with multicultural guests. Students provided written feedback for program evaluation. Authors classified their comments qualitatively. Results: Students mostly responded positively to the class with a significant focus on interacting with the multicultural guests. Students realized the significance of $C D$ in healthcare and reflected deeply on their discussion with the multicultural patients. Students needed more time to interact with multicultural guests from a greater range of cultures represented in Korea. Most did not need English interpretation.

Conclusion: The aim of the class was achieved. Medical students' interaction with multicultural patients may promote the students' understanding and reflection about $C D$ in health care.

Key Words: Cultural competency, Patient safety, Undergraduate medical education, Culturally competent care, Healthcare disparities

\section{Introduction}

Historically, the Korean population was ethnically homogeneous. In recent years, society has grown more culturally diverse. National statistics from the Korean Ministry of the Interior and Safety in 2016 showed 1.76 million Non-Korean residents living in Korea [1]. Furthermore, over 364 thousand patients from 186 countries accessed healthcare services in Korea in 2016 [2]. Therefore, we can see an obvious need to pay attention to cultural diversity (CD) in Korean healthcare.
Doctors should provide optimal care and services to people from various cultural backgrounds [3,4]. Early diversity education focused mainly on cultural traits which were different from mainstream, and educators taught tolerance, skills for using interpreters, and stereotypical health behaviors of specific ethnicities [5]. The early paradigm was criticized for being too prescriptive and educators changed their focus $[4,5]$. The current paradigm is based on the premise that each person cannot be stereotyped as any one of their various cultural backgrounds [3].

While $\mathrm{CD}$ education in the medical field is widely accepted in multiethnic countries, it has yet to be
Received: February 7, 2018 • Revised: March 29, 2018 • Accepted: March 29, 2018 Corresponding Author: HyeRin Roh (https://orcid.org/0000-0002-3879-709X) Department of Medical Education and the Institute for Medical Humanities, Inje University College of Medicine, 75 Bokji-ro, Busanjin-gu, Busan 47392, Korea

Tel: +82.51.890.8811 Fax: +82.51.893.9600 email: hyerinr@gmail.com

*A previous version of this study has been presented at the Korean Medical Education Conference in 2 June, 2017, Daejeon, South Korea.
Korean J Med Educ 2018 Jun; 30(2): 161-166. https://doi.org/10.3946/kjme.2018.91 eISSN: $2005-7288$

(C) The Korean Society of Medical Education. All rights reserved. This is an open-access article distributed under the terms of the Creative Commons Attribution Non-Commercial License (http:// creativecommons.org/licenses/by-nc/3.0/), which permits unrestricted non-commercial use, distribution, and reproduction in any medium, provided the original work is properly cited. 
sufficiently addressed and reported in Korea. Here we share our experiences implementing a CD class in 2017, at a medical school in Korea.

\section{Methods}

\section{Subjects}

One hundred and nine third-year medical students at Inje University College of Medicine attended a CD class in March, 2017. The class was offered as part of an intensive mandatory patient safety course completed prior to students entering their core clinical clerkship [6]. Before the class, we obtained informed consent for this study and video recording, as well as an oath of confidentiality from each student.

\section{Contents and structures of the class}

The aim of the class was to facilitate students to realize the current status of $\mathrm{CD}$ in Korean healthcare and reflect on multicultural patients' experiences of healthcare in Korea.

During the 4-hour class, HR, an experienced surgeon and medical educator, introduced the current statistics from multiculturalism in Korea to draw focus to the need for $\mathrm{CD}$. Then, two Korean doctors and LN, an Australian nurse and medical communications specialist, presented their experiences with $\mathrm{CD}$ from the perspective of the healthcare practitioner. Next, multicultural guests shared brief accounts of their experiences as patients in Korean hospitals. We divided students into 12 small groups to discuss what they wanted to know about the multicultural patients' hospital experiences and list and prioritize questions to ask. Students then submitted their written questions and we verified that they were appropriate, and culturally safe before allowing students to directly ask them to the panel of multicultural guests (Table 1).

\begin{tabular}{|c|c|c|c|}
\hline Process & Time & Contents & $\begin{array}{l}\text { Teaching and } \\
\text { learning } \\
\text { methods }\end{array}$ \\
\hline 1. Class orientation & $20 \mathrm{~min}$ & $\begin{array}{l}\text { Ice breaking } \\
\text { Aims of the class } \\
\text { Informed consent }\end{array}$ & - \\
\hline $\begin{array}{l}\text { 2. Introduction of cultural } \\
\text { diversity }\end{array}$ & $30 \mathrm{~min}$ & $\begin{array}{l}\text { Current national status of multiculturalism } \\
\text { Risks when cultural diversity is neglected } \\
\text { Research results showing patients who visited in Korean hospitals' perspectives }\end{array}$ & $\begin{array}{l}\text { Interactive } \\
\text { lecture with } \\
\text { video clips }\end{array}$ \\
\hline $\begin{array}{l}\text { 3. Experiences of healthcare } \\
\text { professionals }\end{array}$ & $1 \mathrm{hr}$ & $\begin{array}{l}\text { Pediatrician's story } \\
\text { Emergency physician's story } \\
\text { Australian nurse's story }\end{array}$ & $\begin{array}{l}\text { Interactive } \\
\text { lecture }\end{array}$ \\
\hline $\begin{array}{l}\text { 4. Introduction of } \\
\text { multicultural guests }\end{array}$ & $30 \mathrm{~min}$ & $\begin{array}{l}\text { Greetings from the guests } \\
\text { Brief self-introduction about cultural background and past medical history } \\
\text { English interpretation if required }\end{array}$ & - \\
\hline $\begin{array}{l}\text { 5. Listing questions for } \\
\text { multicultural patients }\end{array}$ & $30 \mathrm{~min}$ & $\begin{array}{l}\text { Students discuss and develop questions about multicultural patients' hospital } \\
\text { experiences } \\
\text { Prioritize questions }\end{array}$ & $\begin{array}{l}\text { Small group } \\
\text { discussion }\end{array}$ \\
\hline 6. Question and answer & $1 \mathrm{hr}$ & One question per small group & Forum \\
\hline 7. Closing the class & $10 \min$ & $\begin{array}{l}\text { Summary of the class } \\
\text { Introduction of opportunity to meet multicultural patients during clerkship } \\
\text { Obtain written feedback }\end{array}$ & Debriefing \\
\hline
\end{tabular}




\section{Class preparation}

Two medical doctors participated in the class as experts. Both were faculty members who also worked at Inje University Paik Hospital. One was a paediatrician and the other was an emergency physician. Both had many clinical experiences with multicultural patients and understood the concept of $\mathrm{CD}$ and patient safety.

LN recruited four multicultural guest volunteers from among her acquaintances. We selected a Chinese woman married to a Korean, a Mongolian mother of two children, a Bangladeshi Muslim man, and a white South African woman. Our participants covered the following demographics: Chinese, woman and man from nonEnglish-speaking developing countries (Mongolia and Bangladesh), Westerner, mother, Muslim, and marriage migrant (Table 2). They all had experiences in Korean hospitals. We chose English or Korean speaking participants for interpretation convenience.

Before the class, we held a luncheon meeting with the experts and guests at a restaurant of their choosing and verified the menu with all attendees before the meeting. We explained the objectives and process of the class and the need for confidentiality using supporting documents written in both English and Korean. Experts and guests briefly shared their healthcare experiences in Korea and then we discussed which were most appropriate for the class. We obtained informed consent and an oath of confidentiality from each person before the class.
Before the guests entered the lecture-room, we asked students to respect all participants and consider their nonverbal behaviours and stereotypes in their questions and comments. We also asked students whether they needed English to Korean interpretation and the students requested it. However, as students reported experiencing little difficulty understanding the guests during the class, we tapered interpretation off.

\section{Program evaluation with students' response}

After the class, students wrote feedback including what was good, what needed improving, whether students needed English interpretation, and any other issues they may have encountered. HR classified the contents of the comments in each category qualitatively and then counted the number of comments under each classification.

\section{Results}

\section{Students' response to the class process}

Students indicated that the class progressed satisfactorily $(n=5)$. They said that the multicultural patients' stories were 'moving' and they felt 'touched' $(n=8)$. Students rated the class as new and fresh $(\mathrm{n}=6)$, and fun $(n=2)$. Students said that the experts and guests' vivid descriptions of their experiences made them focus on the

\begin{tabular}{lllll}
\hline \multicolumn{1}{c}{ Table 2. Demographics of } & Multicultural Guests & & & \\
\hline \multicolumn{1}{c}{ Variable } & \multicolumn{1}{c}{ Guests 1 } & \multicolumn{1}{c}{ Guest 2 } & \multicolumn{1}{c}{ Guest 3 } & Guest 4 \\
\hline Gender & Female & Female & Female & Male \\
Age (yr) & $35-40$ & $30-35$ & $30-35$ & $35-40$ \\
Nationality & Chinese & Mongolian & South African & Bangladeshi \\
Native language & Chinese & Mongolian & English & Bengali \\
Religion & Atheist & Catholic & Christian & Muslim \\
Marriage status & Married to Korean & Married to foreigner & Married to Korean & Married to foreigner \\
Past medical history & Breast cancer & Miscarriages & Leg infection & Caregiver for death of friend \\
\hline
\end{tabular}


class $(n=3)$.

\section{What was good about the class}

Students greatly appreciated the opportunity to meet people from diverse cultural backgrounds $(n=28)$. They also expressed that it was good to experience direct face-to-face interaction with multicultural patients $(n=23)$ and hear live cases $(n=20)$, frank opinions $(n=10)$, the hidden truth about the Korean healthcare system ( $n=9)$ from multicultural patients, and real stories from healthcare professionals $(n=8)$. Students also indicated that the interaction between students and guests, and between students and students was good $(n=4)$ (Table 3).

\section{The meaning of the class}

Students commented that the class was valuable and meaningful $(n=7)$. Students said that the class helped them concrete their understanding of the reality of Korean medical care for foreigners $(n=6)$ and cultural differences $(n=4)$. Students said that the class made them reflect deeply on their prejudices $(n=6)$. They also indicated that the class helped them recognize the importance of cultural safety and understand the need for improvement of the attitudes of health care professionals (including the students themselves) $(n=3)$.

\section{Negative points and suggestions for improvement}

Students indicated that the discussion with the multicultural guests was not detailed enough due to a lack of time ( $\mathrm{n}=6)$. One student felt unpleasant to observe some students seemed distracted while guests spoke (Table 3).

Students wanted more contact with patients from more diverse backgrounds ( $\mathrm{n}=11$ ) such as low socioeconomicstatus, non-Korean and non-English speaking persons, low-educated people, immigrant workers, North Korean defectors, women who married Korean men, and homosexuals. In addition, students suggested a longer question and answer session with the multicultural guests $(n=8)$ and some requested additional individual sessions with them $(n=6)$. Students suggested that the introduction of Korea's CD status and lectures from the experts should be shortened $(n=4)$. One student hoped diversity

Table 3. Good and Improvement Points of the Cultural Diversity Class from Students' Responses

\begin{tabular}{lc}
\hline \multicolumn{1}{c}{ Students' responses } & No. of students who wrote in feedback \\
\hline What was good about the class & 28 \\
Meeting people from diverse cultural backgrounds & 23 \\
Direct face-to-face interaction with multicultural guests & 20 \\
Hearing live cases of multicultural guests & 10 \\
Hearing frank opinions from multicultural guests & 9 \\
Hearing hidden truth about the Korean healthcare system for foreigners & 8 \\
Hearing real stories from healthcare professionals & 4 \\
Interaction between students and guests, and between students and students & 6 \\
Negative points & 1 \\
Lack of time & \\
Distracted students & 11 \\
Suggestions for improvement & 8 \\
More contact with patients from more diverse backgrounds & 6 \\
Longer question and answer session with multicultural guests & 4 \\
Additional individual sessions with multicultural guests & 1 \\
Shorten orientation and lecture session of healthcare professionals & \\
Harsher warning about respectful attitudes prior to the class &
\end{tabular}


education could be included in other courses during the curriculum. One student suggested a harsher warning about showing respectful attitudes prior to the class.

\section{Interpretation}

Many students indicated that interpretation was unnecessary because guests spoke English slowly and used easy words $(n=20)$. However, three students indicated that they needed English interpretation. Two students suggested using a professional interpreter, and three students suggested the use of scripts or presentation slides to accompany the guests' stories.

\section{Discussion}

Our study is the first to report the implementation of an educational program to provide students with live accounts of the experiences of multicultural patients in Korea. Our class facilitated students to reflect deeply about $\mathrm{CD}$ and students responded very positively. We believe this could be a valuable starting point for educators considering implementing $\mathrm{CD}$ programs for healthcare in Korea and other traditional monocultures.

In this study, students indicated the need for more time for discussion with multicultural guests of various cultural backgrounds. Previous studies suggested that a minimum of 15 hours of $\mathrm{CD}$ education should run in an integrated and longitudinal manner, from the early years of medical education [3]. Along with lectures and communication skills workshops, cultural immersion programs in the community may help students deeply expand their understanding of $\mathrm{CD}$ and develop culturally safe practice [7].

In this study, because we recruited participants from among our acquaintances as guests and interpreted ourselves, the budget required was quite low. However, if educators want to include a broad range of nonKorean guests, a funding may be necessary to compensate guests for their time and pay for professional interpreters.

Future research is needed: First, we need to objectively investigate the short- and long-term effect of the program. Second, we need to investigate the multicultural experiences of patients and doctors in more detail. Third, we have to develop appropriate educational programs for students, doctors, and faculties in Korea and evaluate them from the perspectives of all stakeholders.

In conclusion, in this study, students' feedback showed that the aims of our class were achieved. Students needed more time to interact with multicultural guests, from a more diverse range of cultures represented in Korea. Most did not need English interpretation. Future research is needed to investigate the effect of the $\mathrm{CD}$ program and multicultural experiences of patients and doctors, and to develop more appropriate educational programs for healthcare professionals.

\section{ORCID:}

HyeRin Roh: https://orcid.org/0000-0002-3879-709X; Lauren Nirta: https://orcid.org/0000-0001-6432-7801

Acknowledgements: The authors would like to extend their sincere thanks and gratitude to the experts, guests and students who participated in this program and provide their valuable feedback.

Funding: No funding provided for this research.

Conflicts of interest: No potential conflict of interest relevant to this article was reported.

Author contributions: Conception and design of the work: $\mathrm{HR}$, LN; data collection, data analysis and interpretation: HR; drafting the article: HR; editing the article together: $\mathrm{HR}$, LN; critical revision of the article: HR, LN; and 
final approval of the version to be published: HR, LN.

\section{References}

1. Ministry of the Interior and Safety, the Korea National Statistical Office. Population and housing census 2016. http://kostat.go.kr/portal/korea/kor_nw/2/9/2/index.board $?$ bmode $=$ read $\& b S e q=\& a S e q=362609 \&$ pageNo $=1$ \& ro $\mathrm{wNum}=10 \&$ navCount $=10 \&$ currPg $=\&$ sTarget $=$ title\&s T $\mathrm{xt}=$. Published 2017. Accessed January 18, 2018.

2. Korea Health Industry Development Institute. Statistics on international patients in Korea, 2016. https://www.khidi.or.kr/ board/view?pageNum = 1 \&rowCnt $=10$ \&nol $=945$ \&linkI $\mathrm{d}=221359$ \& titleId $=164657$ \&menuId $=$ MENU00858\& maxIndex $=00002219799998 \& \operatorname{minIndex}=0000176981$ 9998\&schType $=0 \&$ schText $=\& b$ boardStyle $=\&$ categoryId $=\&$ continent $=\&$ country $=$. Published 2017. Accessed January 18, 2018.
3. Dogra N, Bhatti F, Ertubey C, et al. Teaching diversity to medical undergraduates: curriculum development, delivery and assessment: AMEE GUIDE no. 103. Med Teach. 2016;38(4):323-337.

4. Kumagai AK, Lypson ML. Beyond cultural competence: critical consciousness, social justice, and multicultural education. Acad Med. 2009;84(6):782-787.

5. Reitmanova S. Cross-cultural undergraduate medical education in North America: theoretical concepts and educational approaches. Teach Learn Med. 2011;23(2): 197-203.

6. Roh H, Park SJ, Kim T. Patient safety education to change medical students' attitudes and sense of responsibility. Med Teach. 2015;37(10):908-914.

7. Crampton P, Dowell A, Parkin C, Thompson C. Combating effects of racism through a cultural immersion medical education program. Acad Med. 2003;78(6):595598. 